\title{
Ways of Coping among Nurses in the Context of Maternal and Perinatal Mortality in the Limpopo Province, South Africa
}

\author{
Ntuli TS ${ }^{1}$; Mashego $\mathrm{TAB}^{2}$; Nesengani $\mathrm{DS}^{3}$;Wyatt $\mathrm{G}^{4}$ \\ 1. Department of Public Health, University of Limpopo, Sovenga, South Africa \\ 2. Department of Clinical Psychology, University of Limpopo, Sovenga, South Africa \\ 3. Department of Obstetrics and Gynaecology, University of Limpopo, Sovenga, South Africa \\ 4. Department of Behavioral Medicine, University of California, Los Angeles, United States of America
}

\begin{abstract}
Objective: To determine the coping strategies used by nurses providing maternal and perinatal care in the hospitals of the Limpopo Province, South Africa. Methods: A cross-sectional descriptive study was conducted in public hospitals (1 tertiary, 2 regional and 3 district hospitals). A sample of nurses and unit managers on duty at the time of visit was asked to complete the Ways of Coping Scale (WCS) questionnaire anonymously. Principal Component Analysis was used to test factor structure from the original 32-items WCS questionnaire. Results: A total of 83 nurses participated in the study, of which $98 \%$ were females and (59\%) married. The most frequent coping strategies used were acceptance/adaptation, substance use and emotional eating, denial/avoidance, spiritual and seeking social help. Conclusion: Therefore, it is recommended that psychological support programs should be implemented to deal with stressful situations at workplace
\end{abstract}

Keywords: Coping Strategy;Nurse;Maternity;Limpopo Province

\section{Introduction}

In South Africa (SA), occupational exposure to maternal deaths has become an inevitable part of the daily experiences of the health care workforce ${ }^{[1]}$. The persistent exposure to maternal death may cause cumulative stress and emotional turmoil ${ }^{[2]}$ and have adverse effects on the well-being of nurses and their ability to provide quality work ${ }^{[3,4]}$ Moreover, lack of staff, equipment and infrastructure, and increased workload may also contribute to stress ${ }^{[5,6]}$ burnout and compassion fatigue ${ }^{[7-10]}$ amongst nurses. The level of stress experienced and the extent to which the adverse effects of stress occur depend on how well the individual utilises coping strategies in a hospital setting ${ }^{[1]}$ Knowledge about the coping strategies used by nurses to adapt to a stressful environment can direct local health care teams and policy makers to develop interventions - leading to a healthier work environment with fewer problems. However, little or no information is available on the coping mechanisms used by nurses to deal with stressful working conditions in rural areas of SA. There is a tendency to focus more on the psychopathology and little is done to look at the way such stress can be positively addressed. Addressing stress positively is in line with new trends in positive psychology that focusses on the strength and resilience of individuals in distress and how they are enabled to flourish ${ }^{[12]}$ Therefore, this study was undertaken in an effort to identify coping strategies used by nurses providing maternal and new-born care in the public hospitals of the Limpopo Province, South Africa.

Copyright (C) 2017 Ntuli TS et al (tsntuli@hotmail.com)

doi: 10.18686/jn.v6i4.131

This is an open-access article distributed under the terms of the Creative Commons Attribution Unported License

(http://creativecommons.org/licenses/by-nc/4.0/), which permits unrestricted use, distribution, and reproduction in any medium, provided the original work is properly cited. 


\section{Materials and Methods}

A cross-sectional descriptive study was conducted in six public hospitals (one tertiary; two regional and three district hospitals) of the Limpopo Province, South Africa. The study was conducted over a period of 2 months from May to June 2014. All nurses providing maternal care, including unit managers on duty at the time of visit, were asked to complete the Ways of Coping Scale (WCS) questionnaire anonymously.

Nurses completed the WCS, which is a revised version of the Coping Strategies Procedure developed by Billing and Moos (1981) ${ }^{[13]}$ The WCS comprises of a 32-items scale for measuring active cognitive strategies (11 items), active behavioural strategies (13 items) and avoidance strategies ( 8 items). The questionnaire uses a 3-point Likert scale, ranging from 0 (Not at all) to 2 (Regularly). Billings and Moos (1981) established reliability of the WCS tool with Cronbach alpha scores of 0.54 for active cognitive, 0.50 for active behavioural, and 0.39 for avoidance coping (Billing and Moos, 1981) $)^{[13]}$ In the present study, Cronbach alpha was 0.79 for active cognitive, 0.86 for behavioural, and 0.76 for avoidable coping.

Exploratory factor analysis with Varimax rotation (used in order to extract maximum variance from the data set) was used to test factor structure from the original 32-items WCS questionnaire. A Scree plot was used to determine the number of factors to retain in the factor model and items with loading values less than 0.55 were excluded from the model, as suggested by Comrey and Lee (1992).14 The fit of the model was assessed using the Kaiser-Meyer-Olkin Measure of Sampling Adequacy (KMO) and Bartlett's Test of Sphericity. The data were entered and analysed using SPSS statistical software (Version 13.0 SPSS Inc, Chicago IL)

\subsection{Ethics Statement}

Ethics approval for the study was obtained from the Pietersburg/Mankweng Hospital Complex Research Ethics Committee (PMHREC) of the University of Limpopo in South Africa. The participants were informed of the purpose of the study and gave a written consent for their participation. Anonymity and confidentiality of data was assured by group data analysis without any personal identifiers.

\section{Results}

A total of 83 nurses from six hospitals in the Limpopo Province of SA participated in the study. Of these, most (98\%) were female with 2 to 5 years of experience in maternity wards. Table 1 presents a detailed description of the demographic profile of the participants. Exploratory factor analysis was performed on the 32-items WCS and yielded 10 factors with eigenvalues greater than 1 and, together accounted for $69.9 \%$ of the variance (Table 1). The KMO for the model was 0.619 and Barlett's test of sphericity was significant $(\mathrm{p}<0.001)$. Inspection of the component matrix found that 17 items had loading values greater than the cut-off point of 0.55 suggested by Comrey and Lee (1992).The results obtained from the factor loading matrix limited to 5 factors and 17 items with high loading values is presented in (Table 3). Results from this subsequent factor analysis accounted for $62.5 \%$ of the variance with KMO of 0.63 and a significant Barlett's test of sphericity $(\mathrm{p}<0.001)$. In the final model, factor loading 1 had 6 items which was labelled acceptance/adaptation, factor 2 had 4 items and labelled substance abuse and binge/emotional eating, factor 3 had 2 items labelled denial and avoidance, factor 4 and 5 both had 1 item labelled spiritual and seeking social support, respectively 
Table 1: Demographic information of the participants, $n=83$

\begin{tabular}{|l|c|c|}
\hline & No & \% \\
\hline Gender & & 2 \\
\hline Male & 2 & 98 \\
\hline Female & 81 & \\
\hline Age (years) & & 25 \\
\hline $20-31$ & 20 & 53 \\
\hline $32-49$ & 44 & 22 \\
\hline $50+$ & 18 & \\
\hline Marital status & & 29 \\
\hline Single & 24 & 59 \\
\hline Married & 48 & 12 \\
\hline Widowed & 10 & \\
\hline Education level & & 54 \\
\hline Matric & 44 & 26 \\
\hline Diploma & 21 & 17 \\
\hline Degree & 14 & 3 \\
\hline Post-graduate & 2 & \\
\hline Occupation status & & 12 \\
\hline Manager/assistant & 10 & 74 \\
\hline Registered nurses & 61 & 15 \\
\hline Enrolled nurses & 12 & 22 \\
\hline Years of experience in maternity ward & 18 & 13 \\
\hline$\leq 1$ & 53 & \\
\hline $2-5$ & 11 & \\
\hline$>5$ & & \\
\hline
\end{tabular}

Table 3: Factor analysis of the final five-factors of the coping scale

\begin{tabular}{|l|c|c|c|c|c|}
\hline \multirow{2}{*}{} & \multicolumn{4}{|c|}{ Factors Loadings } \\
\cline { 2 - 6 } & \multicolumn{1}{|c|}{1} & 2 & 3 & 4 & 5 \\
\hline \% of variance & 22.6 & 16.8 & 8.9 & 7.6 & 6.6 \\
\hline Eigenvalues & 3.8 & 2.8 & 1.5 & 1.3 & 1.1 \\
\hline Went over the situation in my mind to try to understand it & $\mathbf{0 . 7 9}$ & 0.03 & -0.05 & 0.04 & -0.14 \\
\hline Told myself things that helped me feel better & $\mathbf{0 . 7 7}$ & 0.15 & 0.13 & 0.17 & 0.01 \\
\hline Tried to see the positive side of the situation & $\mathbf{0 . 7 2}$ & 0.04 & -0.12 & 0.08 & 0.03 \\
\hline Tried to step back from the situation and be more objective & $\mathbf{0 . 7 0}$ & 0.06 & -0.01 & -0.16 & -0.17 \\
\hline Accepted it, nothing could be done & $\mathbf{0 . 6 5}$ & -0.01 & 0.07 & -0.17 & 0.16 \\
\hline Let my feelings out somehow & $\mathbf{0 . 5 8}$ & -0.09 & 0.18 & 0.02 & 0.37 \\
\hline Made a plan of action and followed it & 0.53 & 0.02 & -0.24 & 0.32 & 0.23 \\
\hline Got busy with other things to keep my mind off the problem & 0.52 & -0.04 & 0.30 & 0.44 & 0.12 \\
\hline Tried to reduce tension by smoking more & 0.05 & $\mathbf{0 . 9 1}$ & 0.04 & 0.07 & -0.07 \\
\hline Tried to reduce tension by taking more tranquilizing drugs & -0.15 & $\mathbf{0 . 7 7}$ & 0.02 & 0.34 & 0.11 \\
\hline Tried to reduce tension by eating more & 0.06 & $\mathbf{0 . 7 3}$ & 0.24 & -0.10 & 0.05 \\
\hline Tried to reduce tension by drinking more & 0.21 & $\mathbf{0 . 6 8}$ & 0.18 & -0.19 & -0.04 \\
\hline Avoided being with people in general & 0.07 & 0.18 & $\mathbf{0 . 8 6}$ & 0.11 & 0.04 \\
\hline Refused to believe that it happened & -0.08 & 0.24 & $\mathbf{0 . 8 2}$ & -0.06 & -0.18 \\
\hline Prayed for guidance or strength & -0.01 & 0.04 & 0.01 & $\mathbf{0 . 7 9}$ & -0.03 \\
\hline Talked with friend about the problem & 0.10 & -0.09 & -0.03 & 0.17 & $\mathbf{0 . 7 5}$ \\
\hline Talked with spouse or other relative about the problem & -0.10 & 0.23 & -0.15 & -0.34 & $\mathbf{0 . 6 4}$ \\
\hline Kaiser-Meyer- Olkin Meas
\end{tabular}

Kaiser-Meyer-Olkin Measure of Sampling Adequacy $=0.630$

Bartlett's Test of Sphericity $(\chi 2=519.9, \mathrm{p}<0.001)$ 
Table 2: Factor analysis of the original 32-item coping scale

\begin{tabular}{|c|c|c|c|c|c|c|c|c|c|c|}
\hline & \multicolumn{10}{|c|}{ Factor Loadings } \\
\hline & 1 & 2 & 3 & 4 & 5 & 6 & 7 & 8 & 9 & 10 \\
\hline$\%$ of variance & 19.3 & 11.3 & 7.3 & 6.6 & 5.3 & 4.9 & 4.2 & 4.1 & 3.5 & 3.3 \\
\hline Eigenvalues & 6.2 & 3.6 & 2.4 & 2.1 & 1.7 & 1.6 & 1.4 & 1.3 & 1.1 & 1.1 \\
\hline Tried to see the positive side of the situation & 0.74 & -0.17 & 0.07 & -0.15 & 0.25 & -0.01 & 0.00 & -0.15 & -0.12 & -0.24 \\
\hline Told myself things that helped me feel better & 0.69 & 0.13 & -0.11 & -0.31 & -0.07 & -0.04 & 0.07 & 0.06 & 0.34 & -0.01 \\
\hline Went over the situation in my mind to try to understand it & 0.69 & -0.09 & -0.05 & -0.30 & -0.02 & 0.03 & -0.25 & 0.04 & 0.04 & 0.12 \\
\hline Made a plan of action and followed it & 0.62 & -0.16 & -0.06 & 0.20 & -0.30 & -0.08 & 0.24 & -0.09 & -0.35 & -0.15 \\
\hline Accepted it, nothing could be done & 0.60 & -0.06 & -0.05 & 0.11 & -0.06 & -0.02 & -0.28 & 0.13 & 0.05 & 0.32 \\
\hline Let my feelings out somehow & 0.60 & -0.02 & -0.22 & 0.24 & -0.21 & -0.25 & 0.11 & 0.19 & 0.02 & 0.03 \\
\hline Tried to step back from the situatin and be more objective & 0.59 & -0.09 & 0.02 & -0.30 & 0.19 & -0.05 & -0.16 & -0.20 & 0.39 & -0.07 \\
\hline Got busy with other things to keep my mind off the problem & 0.55 & 0.12 & -0.32 & -0.21 & -0.12 & 0.03 & 0.30 & 0.18 & 0.01 & -0.03 \\
\hline Tried not to act too hastily or follow my first hunch & 0.52 & -0.34 & 0.05 & 0.27 & -0.09 & -0.10 & 0.17 & 0.29 & -0.22 & 0.05 \\
\hline Took things a day at a time & 0.52 & -0.17 & 0.16 & -0.14 & 0.47 & 0.25 & -0.10 & 0.18 & -0.04 & -0.05 \\
\hline Bargained or compromised to get something positive from the & 0.52 & 0.15 & -0.05 & 0.48 & -0.13 & 0.31 & -0.05 & -0.11 & 0.02 & -0.14 \\
\hline Prepared for the worst & 0.51 & -0.18 & 0.36 & -0.28 & 0.03 & 0.12 & -0.07 & -0.28 & -0.06 & 0.05 \\
\hline Got away from things for a while & 0.50 & 0.06 & -0.13 & 0.29 & -0.18 & 0.12 & 0.10 & -0.28 & 0.41 & -0.14 \\
\hline Kept my feeling to myself & 0.48 & 0.41 & -0.47 & 0.02 & 0.29 & -0.15 & -0.12 & -0.09 & -0.13 & -0.05 \\
\hline 1 knew what had to be done and tried to make things work & 0.46 & 0.09 & -0.02 & 0.37 & -0.18 & 0.07 & -0.38 & 0.02 & -0.32 & 0.25 \\
\hline Drew on my past experiences & 0.44 & -0.43 & 0.02 & -0.23 & 0.18 & -0.24 & 0.16 & -0.06 & -0.19 & -0.38 \\
\hline Tried to reduce tension by smoking more & 0.11 & 0.72 & 0.46 & -0.06 & -0.21 & 0.10 & -0.11 & 0.00 & 0.08 & -0.23 \\
\hline Avoided being with people in general & 0.17 & 0.68 & -0.30 & 0.08 & 0.38 & 0.03 & 0.11 & 0.13 & -0.09 & 0.12 \\
\hline Refused to believe that it happened & -0.04 & 0.67 & -0.18 & 0.07 & 0.40 & 0.03 & 0.02 & -0.06 & -0.09 & 0.20 \\
\hline Tried to reduce tension by eating more & 0.23 & 0.63 & 0.43 & -0.11 & -0.01 & -0.25 & -0.04 & 0.11 & -0.23 & -0.06 \\
\hline Tried to reduce tension by drinking more & 0.18 & 0.58 & 0.34 & -0.04 & -0.33 & 0.00 & -0.31 & 0.23 & 0.08 & -0.19 \\
\hline Tried to reduce tension by taking more tranquilizing drugs & 0.01 & 0.57 & 0.47 & -0.09 & -0.11 & 0.04 & 0.35 & -0.06 & -0.18 & -0.13 \\
\hline Tried to reduce tension by exercising more & 0.24 & 0.41 & 0.10 & 0.04 & 0.38 & 0.10 & 0.21 & -0.18 & 0.04 & 0.19 \\
\hline Talked with spouse or other relative about the problem & 0.06 & -0.08 & 0.61 & 0.47 & 0.13 & -0.20 & 0.15 & -0.01 & 0.33 & 0.17 \\
\hline Considered several alternatives for handling the problem & 0.35 & -0.35 & 0.44 & 0.17 & 0.19 & 0.21 & 0.09 & -0.22 & -0.19 & 0.06 \\
\hline Made myself things that helped me feel better & 0.46 & 0.08 & -0.06 & -0.54 & -0.27 & 0.04 & -0.09 & 0.21 & -0.04 & 0.20 \\
\hline Sought help from persons or group with similar experiences & 0.38 & 0.19 & -0.34 & 0.45 & -0.17 & 0.23 & -0.05 & -0.23 & 0.06 & -0.14 \\
\hline Made a promise to myelf that things would be different next time & 0.08 & 0.12 & -0.08 & -0.31 & -0.44 & -0.25 & 0.40 & -0.31 & 0.01 & 0.36 \\
\hline Prayed for guidance or strength & 0.10 & 0.05 & 0.02 & -0.17 & -0.08 & 0.72 & 0.40 & -0.02 & -0.02 & 0.21 \\
\hline Tried to find out more about the situation & 0.48 & -0.04 & 0.34 & 0.24 & 0.15 & -0.51 & 0.11 & -0.02 & 0.11 & 0.26 \\
\hline Took it out on other people when I felt angry or depressed & -0.02 & 0.22 & -0.26 & 0.13 & 0.15 & -0.23 & 0.31 & 0.27 & 0.15 & -0.22 \\
\hline Talked with friend about the problem & 0.22 & -0.25 & 0.22 & 0.11 & 0.07 & 0.32 & 0.20 & 0.64 & 0.16 & 0.01 \\
\hline
\end{tabular}

Kaiser-Meyer-Olkin Measure of Sampling Adequacy $=0.619$

Bartlett's Test of Sphericity $(\chi 2=1332.3, \mathrm{p}<0.001)$

\section{Discussion}

This study focused on identifying coping mechanisms used by nurses in the context of maternal and perinatal mortality. Numerous studies found problem-solving focus as one of the most frequent strategies used by nurses to overcome a stressful environment ${ }^{[15-18]}$ Most healthcare professionals consider looking for the fundamental source of the problem and attempt to manage or change the problem causing the stress. In contrast, in our study, acceptance/adaptation was found to be the important coping strategy used by participants to handle stressful situations. This could be interpreted to mean that being faced with such distress could be perceived as being in a situation where the problem is seen as unalterable and, as such, people feeling that they just have learn to live with it.

Substance use has been mentioned as a common stress-reducing mechanism used by nurses ${ }^{[19,20]}$ and nursing students $^{[21]}$, while high levels of work-related stress have been shown to increase disordered eating ${ }^{[22,23]}$ and lead to poor coping skills ${ }^{[24,25]}$ Not surprisingly, in our study substance use and binge/emotional eating were important coping strategies used by nurses. Reasons for this were not documented in our study, however, factors such as working conditions $^{[8]}$, shortage of staff ${ }^{[26]}$, frequent exposure to perinatal and maternal deaths ${ }^{[27,28]}$ and access to controlled prescription-type drugs, which can increase the risk of drug abuse ${ }^{[29,30]}$, could contribute. It was also noted that the 
negative impact of distress and trauma led to psychological disorders that tend to push individuals towards self-medication in an attempt to bring about some sense of balance in the vulnerable states induced by their circumstances, which means that the effects of trauma history on psychological distress are partially mediated by substance misuse ${ }^{[31]}$.

Our study revealed that, although a denial and avoidance strategy is less used, Intensive Care Unit nurses mainly adopted the coping strategy of denial/avoidance ${ }^{[32]}$. This finding indicates that nurses deny the existence of a problem and withdraw from people, which implies that they use negative coping mechanisms ${ }^{[33]}$. Psychological support and counselling may help nurses in this rural province handle stressful situations better. This study found that another important strategy used by nurses to manage stressful situations is a spiritual coping strategy. Studies in faith and non-faith-based health facilities found that a spiritual coping strategy is the strategy most commonly used by clinical nurses to cope with occupational stress ${ }^{[17,18,34]}$. Spirituality is not unexpected in our settings since most nurses pray every morning before the shift starts. Finally, seeking social support involves efforts used to obtain information and emotional support from friends, spouses or other relatives about the problem. In our study, seeking social support was the least method used by participants; however, this strategy has always been an important coping strategy for confronting and handling stressful situations ${ }^{[35-37]}$.

\section{Conclusion}

This study has yielded important findings that could be used to inform decision-making in terms of improving the workplace environment. The results of our study suggest that negative coping is the most frequently used strategy, which is an ineffective way of coping. 33 Therefore; it is recommended that psychological support programs should be implemented to deal with stressful situations at work.38

\section{Acknowledgements}

Thanks to the financial and mentoring support obtained from the Phodiso Project of the University of Limpopo, in collaboration with UCLA. The investigators would like to thank the data collectors and capturers for their assistance during the field work.

\section{References}

1. National Department of Health. South Africa saving mothers 2011-2013: Sixth report on confidential enquiries into maternal deaths in South Africa. Pretoria: National Department of Health; 2015. [cited 2016 April 05] Available from: http:// www.doh.gov.za

2. Knezevic B, Milosevic M, Golubic R, Belosevic L, Russo A, Mustajbegovic J. Work-related stress and work ability among Croatian university hospital midwives. Midwifery. 2011 Apr;27(2):146-53. doi: 10.1016/j.midw.2009.04.002.

3. Peterson J, Johnson M, Halvorsen B et al. Where do nurses go for help? A qualitative study of coping with death and dying. Int. J. Palliat. Nurs. 2010;16(9): 432-438.

4. Adib-Hajbaghery M, Khamechian M, Alavi NM. Nurses' perception of occupational stress and its influencing factors: A qualitative study. Iran J Nurs Midwifery Res. 2012 Jul;17(5):352-9.

5. Lu DM, Sun N, Hong S, Fan YY, Kong FY, Li QJ. Occupational stress and coping strategies among emergency department nurses of China. Arch Psychiatr Nurs. 2015 Aug;29(4):208-12. doi: 10.1016/j.apnu.2014.11.006.

6. Zhou H, Gong YH. Relationship between occupational stress and coping strategy among operating theatre nurses in China: a questionnaire survey. J Nurs Manag. 2015 Jan;23(1):96-106. doi: 10.1111/jonm.12094.

7. Kekana HP. du Rand EA, van Wyk NC. Job satisfaction of registered nurses in a community hospital in the Limpopo Province in South Africa. Curationis. 2007 Jun;30(2):24-35.

8. Nyathi $\mathrm{M}$ and Jooste $\mathrm{K}$. Working conditions that contribute to absenteeism among nurses in a provincial hospital in the Limpopo Province. Curationis. 2008 Mar;31(1):28-37 
9. Delobelle P, Rawlinson JL, Ntuli S, Malatsi I, Decock R, Depoorter AM. Job satisfaction and turnover intent of primary healthcare nurses in rural South Africa: a questionnaire survey. J Adv Nurs. 2011 Feb;67(2):371-83. doi: $10: 1111 / \mathrm{j} / 1365-2648.2010 .05496 . x$

10. Mashego TAB, Nesengani DS, Ntuli TS, Wyatt G. Burnout, compassion fatigue and compassion satisfaction among nurses in the context of maternal and perinatal deaths. Journal of Psychology in Africa 2017. 26(5):469-72

11. Wang W, Kong AW, Chair SY. Relationship between job stress level and coping strategies used by Hong Kong nurses working in an acute surgical unit. Appl Nurs Res. 2011 Nov;24(4):238-43. doi: 10.1016/j.apnr.2009.09.003.

12. Seligman, MEP. Flourish: A visionary New Understanding of Happiness and Well-being. 2011. Free Press

13. Billings AG, Moos RH. The role of coping responses and social resources in attenuating the stress of life events. J Behav Med. 1981 Jun; 4(2):139-57.

14. Comrey, A., \& Lee, H. (1992). A first course in factor analysis (2nd ed.). Hillsdale: Erlbaum.

15. Lim J, Bogossian F, Ahern K. Stress and coping in Australian nurses: a systematic review. Int Nurs Rev. 2010 Mar; 57(1):22-31. doi: 10.1111/j.1466-7657.2009.00765.x.

16. Rothmann S, Jorgensen LI, Hill C. Coping and work engagement in selected South African organisations. SA J of Industrial Psychology. 2011. 37(1), 01-11.

17. Fathi A, Nasae T, Thiangchanya P. Workplace stressors and coping strategies among public hospital nurses In Medan, Indonesia. Nurse Media Journal of Nursing. 2012; 2(1): 315-324.

18. Eslami Akbar R, Elahi N, Mohammadi E, Fallahi Khoshknab M. What Strategies Do the Nurses Apply to Cope With Job Stress?: A Qualitative Study. Glob J Health Sci. 2015 Sep 28;8(6):55-64. doi: 10.5539/gjhs.v8n6p55.

19. Kunyk D. Substance use disorders among registered nurses: prevalence, risks and perceptions in a disciplinary jurisdiction. $\mathrm{J}$ Nurs Manag. 2015 Jan;23(1):54-64. doi: 10.1111/jonm.12081.

20. Epstein PM, Burns C, Conlon HA. Substance abuse among registered nurses. AAOHN J. 2010 Dec; 58(12):513-6.

21. Nair JM, Nemeth LS, Sommers M, Newman S, Amella E. Alcohol Use, Misuse, and Abuse Among Nursing Students: A Photovoice Study. J Addict Nurs. 2016 Jan-Mar;27(1):12-23. doi: 10.1097/JAN.0000000000000107.

22. King KA, Vidourek R, Schwiebert M. Disordered eating and job stress among nurses. J Nurs Manag. 2009 Nov;17(7):861-9. doi: 10.1111/j.1365-2834.2009.00969.x.

23. Mota MC, De-Souza DA, Rossato LT et al. Dietary patterns, metabolic markers and subjective sleep measures in resident physicians. Chronobiol Int. 2013 Oct;30(8):1032-41. doi:10.3109/07420528.2013.796966.

24. van Strien T, Herman CP, Anschutz DJ, Engels RC, de Weerth C. Moderation of distress-induced eating by emotional eating scores. Appetite. 2012;58:277-284

25. van Strien T, Cebolla A, Etchemendy E, Gutiérrez-Maldonado $\mathrm{J}$ et al. Emotional eating and food intake after sadness and joy. Appetite. 2013 Jul;66:20-5. doi: 10.1016/j.appet.2013.02.016.

26. Ntuli ST, Ogunbanjo GA. Midwifery workforce profile in Limpopo Province referral hospitals. Afr J Prim Health Care Fam Med. 2014 Apr 25;6(1):E1-4. doi: 10.4102/phcfm.v6i1.573.

27. Ntuli TS, Malangu N. An investigation of the stillbirths at a tertiary hospital in Limpopo province of South Africa. Glob J Health Sci. 2012 Sep 24;4(6):141-7. doi: 10.5539/gjhs.v4n6p141.

28. Ntuli TS, Mabina Mogale M, Francis LM Hyera FLM, Naidoo S, An investigation of maternal mortality at a tertiary hospital of the Limpopo province of South Africa. Southern African Journal of Infectious Diseases 2017; 32(2):73-76 https://doi.org/10.1080/23120053.2017.1293902

29. Monroe TB, Kenaga H, Dietrich MS, Carter MA, Cowan RL. The prevalence of employed nurses identified or enrolled in substance use monitoring programs. Nurs Res. 2013 Jan-Feb;62(1):10-5. doi: 10.1097/NNR.0b013e31826ba3ca.

30. Starr KT. The sneaky prevalence of substance abuse in nursing. Nursing. 2015 Mar;45(3):16-7. doi: 10.1097/01.NURSE.0000460727.34118.6a.

31. Garland E.L, Pettus-Davis,C, Howard M.D. Self-Medication among traumatized youth ; Structural equation modelling of pathways between trauma history, substance misuse and psychological distress. J Behav Med. 2013 April 36(2):175-185

32. Zyga S, Mitrousi S, Alikari V, Sachlas A, Stathoulis J et al. Assessing factors that affect coping strategies among nursing personnel. Mater Sociomed. 2016 Apr;28(2):146-50. doi: 10.5455/msm.2016.28.146-150.

33. Hirsch CD, Barlem ELD, Almeida LK, Tomaschewski-Barlem JG et al. Coping strategies of nursing students for dealing with university stress. Rev Bras Enferm. 2015;68(5):501-8. DOI: http://dx.doi.org/10.1590/0034-7167.2015680503i

34. Bakibinga P, Vinje HF, Mittelmark M. The role of religion in the work lives and coping strategies of Ugandan nurses. J Relig Health. 2014 Oct; 53(5):1342-52. doi: 10.1007/s10943-013-9728-8.

35. Harris, L. J. M. Exploring how nurses manage workplace stress. Journal of Hospice and Palliative Nursing 2013. 15(8), $446-454$.

36. Hinderer KA. Reactions to patient death: the lived experience of critical care nurses. Dimens Crit Care Nurs. 2012 Jul-Aug;31(4):252-9. 
37. Jahanshahi, M., Jnat alipoor, Z., Nasiri, M., Navabi, N., Shirinkam, F., \& Karimi, H. (2014). Job stressors, coping, strategies and its relationship with mental health status. The Journal of Urmia Nursing and Midwifery Faculty, 12(8), 741-750.

38. Zyga S, Tsiros H, Malliarou M, Stathoulis J, Babatsikou F, Lavdaniti M et al. Intensification of renal nurses' self- esteem: A Pilot St udy. I nter nat ional Journal of Caring Sciences. 2012; 5(3): 320-7 